\title{
CARACTERIZACIÓN DE ESPECIES DE Fusarium CAUSANTES DE PUDRICIÓN DE RAÍZ DEL TRIGO EN EL BAJÍO, MÉXICO
}

\section{CHARACTERIZATION OF Fusarium SPECIES CAUSING ROOT ROT OF WHEAT IN THE BAJIO, MEXICO}

\author{
Santos Gerardo Leyva-Mir ${ }^{1}$, Hans Errol Vega-Portillo ${ }^{1}$, Héctor Eduardo Villaseñor-Mir ${ }^{2}$, Bertha \\ Tlapal-Bolaños ${ }^{1}$, Mateo Vargas-Hernández ${ }^{3}$, Moisés Camacho-Tapia ${ }^{4}$, Juan Manuel Tovar-Pedraza ${ }^{1 *}$ \\ ${ }^{1}$ Departamento de Parasitología Agrícola, Universidad Autónoma Chapingo, 56230, Texcoco, Estado \\ de México, México. \\ ${ }^{2}$ Campo Experimental del Valle de México, Instituto Nacional de Investigaciones Forestales, Agrícolas \\ y Pecuarias, Coatlinchán, 56250, Texcoco, Estado de México, México. \\ ${ }^{3}$ Departamento de Suelos, Universidad Autónoma Chapingo, 56230, Texcoco, Estado de México, \\ México. \\ ${ }^{4}$ Fitopatología, Campus Montecillo, Colegio de Postgraduados, Montecillo, 56230, Texcoco, Estado de \\ México, México. \\ * Autor para correspondencia: jmtovar@colpos.mx
}

\section{RESUMEN}

Los objetivos de este estudio fueron identificar las especies de Fusarium causantes de pudrición de raíz en trigos producidos en el Bajío de México, además de determinar la respuesta de 28 variedades de trigo a la enfermedad. En 2014 y 2015 se obtuvieron aislados de Fusarium spp. a partir de muestras de trigo con síntomas de fusariosis. Los aislados fúngicos se identificaron mediante caracterización morfológica y análisis de secuencias ITS y TEF-1 $\alpha$, así como el uso de iniciadores específicos para la detección de especies de Fusarium. Un aislado representativo de cada especie de Fusarium obtenida se incrementó para verificar su patogenicidad a través de la inmersión de semillas de 28 variedades de trigo en una suspensión de conidios. Los resultados de la caracterización morfológica y análisis de secuencias, así como las pruebas de patogenicidad, indicaron que Fusarium proliferatum y $F$. graminearum son las principales especies causantes de la pudrición de raíz en trigo cultivado en el Bajío de México. Entretanto, la respuesta a la inoculación indicó que las variedades Gálvez M87, Castrejón F97 y Maya S2007 fueron las más tolerantes a la enfermedad, mientras que Monarca F2007 y Batán F96 fueron las variedades más susceptibles.

Palabras clave: Fusarium, trigo, Triticum aestivum, Fusarium proliferatum, Fusarium graminearum, microscopía electrónica de barrido.

\section{ABSTRACT}

The objectives of this study were to identify Fusarium species causing root rot in wheat produced in the Bajío of Mexico, and to determine the response of 28 wheat varieties to this disease. Fusarium spp. isolates were obtained from samples with root rot symptoms in 2014 and 2015. The fungal isolates were identified by morphological characterization and sequence analysis of ITS and TEF-1 $\alpha$, and also using specific primers for the detection of Fusarium species. Pathogenicity of a representative isolate of each Fusarium species was verified by immersion of seeds of 28 wheat varieties in a conidial suspension. The results of the morphological characterization, sequence analysis, and pathogenicity 
tests indicated that Fusarium graminearum and $F$. proliferatum are the main species causing root rot in wheat grown in the Bajío of Mexico. In addition, the response to inoculation indicated that varieties Galvez M87, Castrejón F97, and Maya S2007 were the most tolerant to the disease, while Monarch Batan F96 and F2007 were more susceptible.

Key words: Fusarium, wheat, Triticum aestivum, Fusarium proliferatum, Fusarium graminearum, scanning electron microscopy.

\section{INTRODUCCIÓN}

En México, la producción de trigo (Triticum aestivum L.) del ciclo primavera-verano (P-V) 2012 fue de 184 mil t obtenidas en una superficie de $86 \mathrm{mil} \mathrm{ha,} \mathrm{con} \mathrm{rendimiento} \mathrm{de} \mathrm{2,17} \mathrm{t} \mathrm{ha}{ }^{-1}$, que se concentró en 28 municipios que produjeron el $72 \%$ del total nacional. Los principales estados productores de trigo secano son: Tlaxcala, Oaxaca, Guanajuato, Jalisco, Zacatecas, Puebla, Durango, Michoacán, Morelos, Hidalgo y Estado de México (SIAP, 2014).

El género Fusarium tiene distribución mundial, varias de sus especies son fitopatógenas e infectan a una amplia gama de cultivos, incluyendo maíz (Zea mays L.) trigo (Triticum spp.), avena (Avena sativa L.) y cebada (Hordeum vulgare L.). Fusarium spp. es un problema agrícola importante debido a que reduce la calidad y el rendimiento $y$, más importante, por producir micotoxinas responsables de enfermedades graves en los seres humanos y los animales (Nicolaisen et al., 2009). A nivel mundial, F. culmorum, F. graminearum, F. pseudograminearum, F. avenaceum, F. acuminatum, $F$. crookwellense y $F$. poae son las principales especies causantes de pudrición de raíz en plantas de trigo (Cook, 2010). En México, Gilchrist-Saavedra et al. (2005) reportaron Fusarium graminearum, F. avenaceum, F. equiseti y Microdochium nivale como las especies asociadas a síntomas de pudrición de raíz y tizón de la espiga en algunas zonas trigueras.

Las enfermedades causadas por Fusarium spp. se encuentran prácticamente en todas las áreas del mundo donde se produce trigo, y pueden ser muy agresivas en climas húmedos; en las zonas donde la humedad es baja, la infección la causa casi de manera exclusiva el inóculo presente en residuos de cereales infectados que permanecen en el suelo. El patógeno invade directamente la base de los tallos, cerca o debajo de la superficie del suelo, o entra a la planta a través de las raíces (Cook, 2010).

En el Bajío, México, las áreas con trigo se establecen en los meses de diciembre y enero, generalmente se usan densidades de $300 \mathrm{~kg} \mathrm{ha}^{-1}$ (Solis et al., 2007). La fusariosis de la espiga se observó en el Altiplano de Jalisco, aunque no se precisa que especies son responsables en dicha región, sin embargo, se ha distribuido en toda la región del Bajío. La zona donde se realizó la investigación es de tipo seca a semi seca. Las incidencias de la fusariosis pueden ser del $60 \%$ en campo, y su severidad va del $10 \%$. Los objetivos de este estudio fueron identificar las especies del genero Fusarium causantes de la pudrición de raíz del trigo en campos del Bajío de México, mediante caracterización morfológica, análisis de secuencias y pruebas de patogenicidad $y$, además, evaluar la respuesta de 28 variedades de trigo a la infección por Fusarium spp.

\section{MATERIALES Y MÉTODOS}

\section{Sitios de muestreo}

Durante dos muestreos dirigidos realizados en los ciclos 2014 y 2015, se recolectaron 10 plantas de trigo con síntomas evidentes de pudrición de raíz en 20 sitios de muestreo seleccionados aleatoriamente y distribuidos en el Municipio de Pénjamo, estado de Guanajuato, perteneciente al Bajío que es una de las zonas con mayor producción de trigo en México.

\section{Aislamiento y purificación de Fusarium spp.}

Las plantas de trigo recolectadas se lavaron con agua corriente para eliminar el exceso de suelo y facilitar la evaluación de proporción de lesiones de la raíz. Después se cortaron fragmentos de $0,5 \mathrm{~cm}$, se desinfestaron $3 \mathrm{~min}$ con hipoclorito de sodio al $1,5 \%$, se lavaron tres veces con agua destilada estéril y se secaron en papel absorbente estéril. Estos fragmentos de raíz se colocaron en placas Petri conteniendo medio de cultivo agar papa dextrosa (PDA) (Difco ${ }^{\circledR}$, EE.UU.) con $50 \mathrm{mg} \mathrm{L}^{-1}$ de sulfato de estreptomicina $\left(\right.$ Sigma $^{\circledR}$, EE.UU.). Las cajas se incubaron a $25^{\circ} \mathrm{C}$ bajo luz blanca continua, se revisaron cada $24 \mathrm{~h}$ hasta observar el crecimiento micelial, y las colonias se transfirieron a nuevas cajas Petri con PDA para aumentar e inducir la esporulación. Al momento de la esporulación, los aislados se purificaron mediante la transferencia de una simple espora individual a placas Petri con PDA fresco. Los aislados puros (monospóricos) se conservaron a $-80^{\circ} \mathrm{C}$ en tubos criogénicos conteniendo glicerol al $15 \%$. 


\section{Caracterización morfológica}

De los aislados monospóricos obtenidos, se transfirieron a PDA fresco las colonias que contenían micelio del mismo color y hábito de crecimiento, y así se observaron dos tipos de crecimiento en colonias con $10 \mathrm{~d}$ de crecimiento. Los aislados de Fusarium se caracterizaron mediante la observación y el registro de caracteres morfológicos usando microscopía óptica con un microscopio compuesto (Olympus, Tokyo, Japón). La identificación morfológica de las especies de Fusarium se hizo con las claves específicas y descripciones reportadas por Nelson et al. (1983) y Leslie y Summerell (2006).

\section{Caracterización mediante microscopía electrónica de barrido (MEB)}

Para la preparación de muestras en MEB se cultivó un aislado representativo de cada especie de Fusarium, en cajas Petri con medio de cultivo agar-agua (AA) por $12 \mathrm{~d}$ para observar las diferentes estructuras de reproducción asexual, y después se cortaron fragmentos de $5 \mathrm{~mm}^{3}$ de medio de cultivo con crecimiento micelial y esporulación abundante. Dichas muestras se fijaron en glutaraldehído al $2,5 \%$ en buffer de fosfatos Sorensen's 0,1 M pH 7,2 (Bozzola y Rusell, 2004) por $24 \mathrm{~h}$ y se lavaron tres veces con el buffer de fosfatos antes mencionado (5 min cada vez). Las muestras se deshidrataron en una serie gradual de concentraciones de etanol (30, 40, 50, 60, 70, 80 y $90 \%$ ) por $45 \mathrm{~min}$ en cada una, y finalmente en etanol absoluto tres veces (20 min entre cada cambio). Las muestras se secaron con $\mathrm{CO}_{2}$ en una secadora de punto crítico Sandri-780 (Tousimis Research Corporation $^{\circledast}$, EE.UU.), luego se colocaron y se orientaron sobre un portamuestras usando una cinta doble adhesiva de carbón y se recubrieron con oro por 4 min en una ionizadora JFC-1100 (Jeol ${ }^{\circledR}$, Japón). Las muestras se observaron en un microscopio electrónico de barrido (JSM 6390, Jeol ${ }^{\circledR}$, Japón) operando a $15 \mathrm{Kv}$ (Bozzola y Rusell, 2004). El ancho y largo se registró en 50 macroconidios, microconidios y fiálides en los aislados representativos.

\section{Extracción, amplificación y secuenciación de DNA}

La extracción del ADN total se realizó a partir de micelio de colonias de $8 \mathrm{~d}$ de crecimiento en medio de cultivo PDA con el kit DNeasy (Qiagen ${ }^{\circledR}$, EE.UU.) y el protocolo recomendado por el fabricante. El ADN se almacenó a $-20^{\circ} \mathrm{C}$ para su uso en la amplificación.

Los espaciadores transcritos internos (ITS1 e ITS2) se amplificaron con la reacción en cadena de la polimerasa (PCR) usando los iniciadores
ITS1 (5'-TCCGTAGGTGAACCTGCGG-3') e ITS4 (5'-TCCTCCGCTTATTGATATGC-3') (White et al., 1990). Mientras que parte de la secuencia del gen del factor de elongación de la traducción (TEF-1 $\alpha$ ) se amplificó con los iniciadores EF-1 (5' -ATGGGTAAGGA(A/G)GACAAGAC-3') y EF-2 (5'- GGA(A/G)GTACCAGT(G/C) ATCATGTT-3') (O’Donnell et al., 1998). Además, se usaron los iniciadores PRO1/PRO2, VER1/ VER2 y SUB1/SUB2, los cuales son específicos a $F$. proliferatum, F. verticillioides y $F$. subglutinans, respectivamente (Mulé et al., 2004). Para la discriminación entre $F$. proliferatum y $F$. verticillioides se usaron los iniciadores verITS-F y proITS-R (Visentin et al., 2009), y ambos se usaron en combinación con los iniciadores universales ITS1/ITS4 (White et al., 1990), respectivamente. Los iniciadores se sintetizaron en la compañía Integrated DNA Technologies (IDT ${ }^{\circledR}$, EE.UU.).

Las reacciones de PCR se realizaron en un termociclador (modelo PTC-150, MJ Research ${ }^{\circledR}$, EE.UU.) con la siguiente mezcla de reacción en un volumen final de $25 \mu \mathrm{L}$ : 1X de solución buffer de PCR, $200 \mu \mathrm{M}$ de desoxinucleótidos trifosfato (dNTP's), 10 pmoles del iniciador antisentido, 10 pmoles de iniciador sentido, 1 unidad de Taq DNA polimerasa (Promega ${ }^{\circledR}$, EE.UU.), 2 $\mathrm{mM}$ de $\mathrm{MgCl}_{2}$ y se completó el volumen con agua libre de nucleasas (agua grado Mili-Q). El programa térmico usado en la amplificación de los ITS's, consistió en una temperatura de $94^{\circ} \mathrm{C}$ por $2 \mathrm{~min}$, luego 35 ciclos a $94-55-72^{\circ} \mathrm{C}$ por 20-25-50 s y una extensión final de $5 \mathrm{~min}$ a $74^{\circ} \mathrm{C}$. Para la amplificación de parte del gen TEF y la discriminación entre $F$. proliferatum, $F$. subglutinans y $F$. verticillioides se siguió el programa $95-50-72$ por $50-50-60$ s durante 35 ciclos (White et al., 1990; Nazar et al., 1991; Mulé et al., 2004).

Al término de las reacciones de PCR, los productos se sometieron a electroforesis en un gel de agarosa al 1,5\% teñido con $0,5 \mu \mathrm{g} \mu \mathrm{L}^{-1}$ de bromuro de etidio, incluyendo un testigo negativo y un marcador de peso molecular ladder-100 (Axygen ${ }^{\circledR}$, EE.UU.). Los fragmentos amplificados por PCR con los iniciadores EF-1/ EF-2 e ITS1/ITS4 se secuenciaron directamente y los resultados se compararon con las secuencias disponibles en el banco de genes (GenBank) del Centro Nacional de Información Biotecnológica (NCBI).

\section{Prueba de patogenicidad en variedades de trigo}

Colonias de un aislado representativo, de cada una de las dos especies de Fusarium diferenciadas mediante caracterización morfológica, se incrementaron en cajas Petri con medio de 
cultivo AA. Una suspensión de conidios de cada aislado de Fusarium se preparó en $1000 \mathrm{~mL}$ agua destilada estéril. Cada suspensión se ajustó a una concentración de $1 \times 10^{6}$ conidios $\mathrm{mL}^{-1}$. La inoculación de la suspensión de esporas de cada especie de Fusarium se efectuó en semillas de 28 variedades de trigo comúnmente sembradas en el estado de Guanajuato. Para esto, 80 semillas de cada variedad se colocaron por $24 \mathrm{~h}$ en cajas Petri que contenían las suspensiones de conidios ya descritas. Las semillas se sembraron en macetas de plástico con suelo esterilizado y humedecido, y se transfirieron cinco semillas a cada maceta, y se usaron cuatro repeticiones. Diez semillas de cada variedad que fueron inmersas únicamente en agua destilada estéril, sirvieron como testigo. Las macetas se colocaron en un invernadero a $22 \pm 2^{\circ} \mathrm{C}$ y $95 \%$ de humedad relativa con un humificador por $5 \mathrm{~d}$. Los síntomas se registraron cada $24 \mathrm{~h}$. Los datos de evaluación de germinación se registraron $5 \mathrm{~d}$ después de la siembra en invernadero. Para las variables necrosis de raíz, se obtuvo la proporción de necrosis en porcentaje con respecto a la raíz, longitud de raíz y longitud de follaje, los datos se tomaron $12 \mathrm{~d}$ después de la germinación de las plántulas. La prueba completa se realizó dos veces.

\section{Análisis estadístico}

El diseño experimental fue bloques completos al azar, los cuales fueron constituidos por 28 variedades (tratamientos) y se evaluaron las variables: germinación, porcentaje de necrosis en raíz, longitud de raíz y longitud de follaje, con cuatro repeticiones y un testigo absoluto. Con los datos de las cuatro variables se realizó un ANDEVA usando el procedimiento GLM (SAS 9.1.3, SAS Institute, Cary, NC, EE.UU.). Las medias de los tratamientos se compararon con la prueba de Fisher (LSD) $(p \leq 0,05)$.

\section{RESULTADOS Y DISCUSIÓN}

\section{Aislamiento y purificación de Fusarium spp.}

En todas las muestras se obtuvo Fusarium, a los $10 \mathrm{~d}$ de crecimiento de las colonias monospóricas de Fusarium, se observaron dos tipos de colonias en el medio de cultivo PDA. El 60\% de los aislados presentaron colonias purpura-violeta y $40 \%$ mostraron crecimiento micelial con coloración blanco-amarillento.

\section{Caracterización morfológica}

Los aislados de Fusarium que presentaron colonias con coloración purpura-violeta en medio PDA y pulpa de papa, desarrollaron macroconidios, microconidios y polifialides. Los microconidios tenían forma de tabique con la base aplanada, sin septos, de 4,6-10 × 1,6-2,5 $\mu \mathrm{m}$ (Fig.
1 A, B y C) y producidos en cadenas cortas. Los macroconidios fueron alargados, relativamente rectos, con paredes delgadas, de 24-33 × 2-2,3 $\mu \mathrm{m}$, con 3-5 septos, célula apical curvada y la célula basal ligeramente desarrollada (Fig. 1 E, I y J). Las polifialides fueron largas (Fig. 1K). Todas las características observadas en microscopía de luz y MEB fueron consistentes con las reportadas por Leslie y Summerell (2006) para Fusarium proliferatum (Teleomorfo: Gibberella intermedia). Asimismo, esta especie fitopatógena es el principal agente causal del tizón de la espiga (Chehri et al., 2010) y pudrición de raíz (Hajieghrari, 2009) del trigo en Irán.

Las observaciones en MEB mostraron macroconidios y microconidios muy similares en forma y tamaño que coinciden con los reportados para F. verticillioides (Leslieetal., 2004). La diferencia morfológica predominante para diferenciar a $F$. proliferatum de $F$. verticillioides es la formación de polifialides para el caso de F. proliferatum, las cuales fueron abundantes durante la examinación morfológica. Otra característica para diferenciar entre $F$. verticillioides y $F$. proliferatum, es que esta última especie forma cadenas de microconidios cortas, como en el presente estudio (Leslie y Summerell, 2006).

Las colonias de los aislados de Fusarium con coloración blanca-amarillenta en medio PDA (Fig. 2 A y B) y pulpa de papa (Fig. 2 A y B), mostraron las siguientes características morfológicas: macroconidios alargados, delgados, uniformes, de 22-48 × 2,5-4,2 $\mu \mathrm{m}$, con paredes delgadas, con 5 o 6 septos, y con la superficie ventral recta y el lado dorsal suavemente arqueado; además, con frecuencia se observó la célula apical alargada y curva, la cual se adelgaza abruptamente hacia un punto, mientras que la célula basal presentó forma de pie (Fig. 2D-G). No se observó la formación de microconidios en los medios de cultivo usados. Las clamidosporas fueron globosas, intercalares y producidas en cadenas. Todas estas características corresponden con las descritas por Leslie y Summerell (2006) para aislados de Fusarium graminearum (Teleomorfo: Gibberella zeae). De manera similar, F. graminearum es la especie predominante causante del tizón de la espiga del trigo en regiones húmedas de EE.UU. (Xu et al., 2008), Argentina (Moschini et al., 2001; Álvarez et al., 2010), China (Gale et al., 2002), Kenia (Muthomi et al., 2007), Irán (Chehri et al., 2010), Australia y sur de Europa (Cook, 2010). La importancia de la detección de esta especie radica en que los granos infectados por F. graminearum pueden contener niveles altos de micotoxinas como tricotecenos y zearalenona, los cuales son altamente dañinos para la salud humana y del ganado (Chelkowski et al., 2000). 

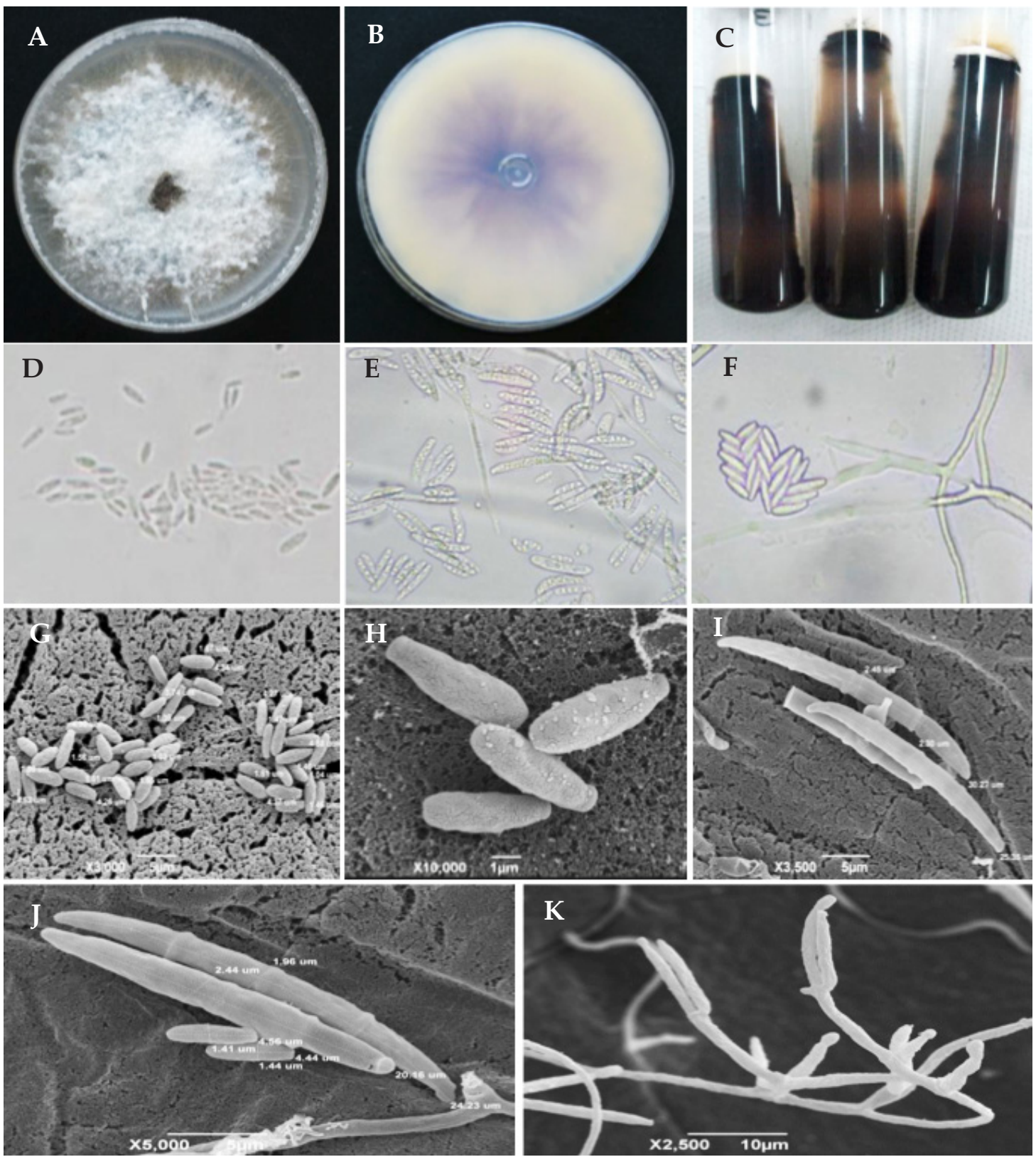

Fig. 1. Colonias y estructuras de reproducción de Fusarium proliferatum. A y B) Colonia con crecimiento micelial de $\mathbf{1 0}$ días en medio de cultivo agar papa dextrosa; C) Colonia cultivada 10 días en tubos con medio de cultivo pulpa de papa; D) Microconidios; E) Macroconidios; F) Fialides; G-H) Microconidios vistos en microscopio electrónico de barrido (MEB); I-J) Macroconidios vistos en MEB; K) Polifialides vistas en MEB. Barras $=10 \mu \mathrm{m}$.

Fig. 1. Colonies and reproductive structures of Fusarium proliferatum. A and B) Colony with mycelial growth of $\mathbf{1 0}$ days on a potato dextrose agar medium; C) Colony cultured for $\mathbf{1 0}$ days in tubes with potato pulp medium; D) Microconidia; E) Macroconidia; F) Phialides; G-H) Microconidia as seen by scanning electron microscopy (SEM); I-J) Macroconidia as seen by SEM; K) Polyphialides as seen by SEM. Bars $=10 \mu \mathrm{m}$. 

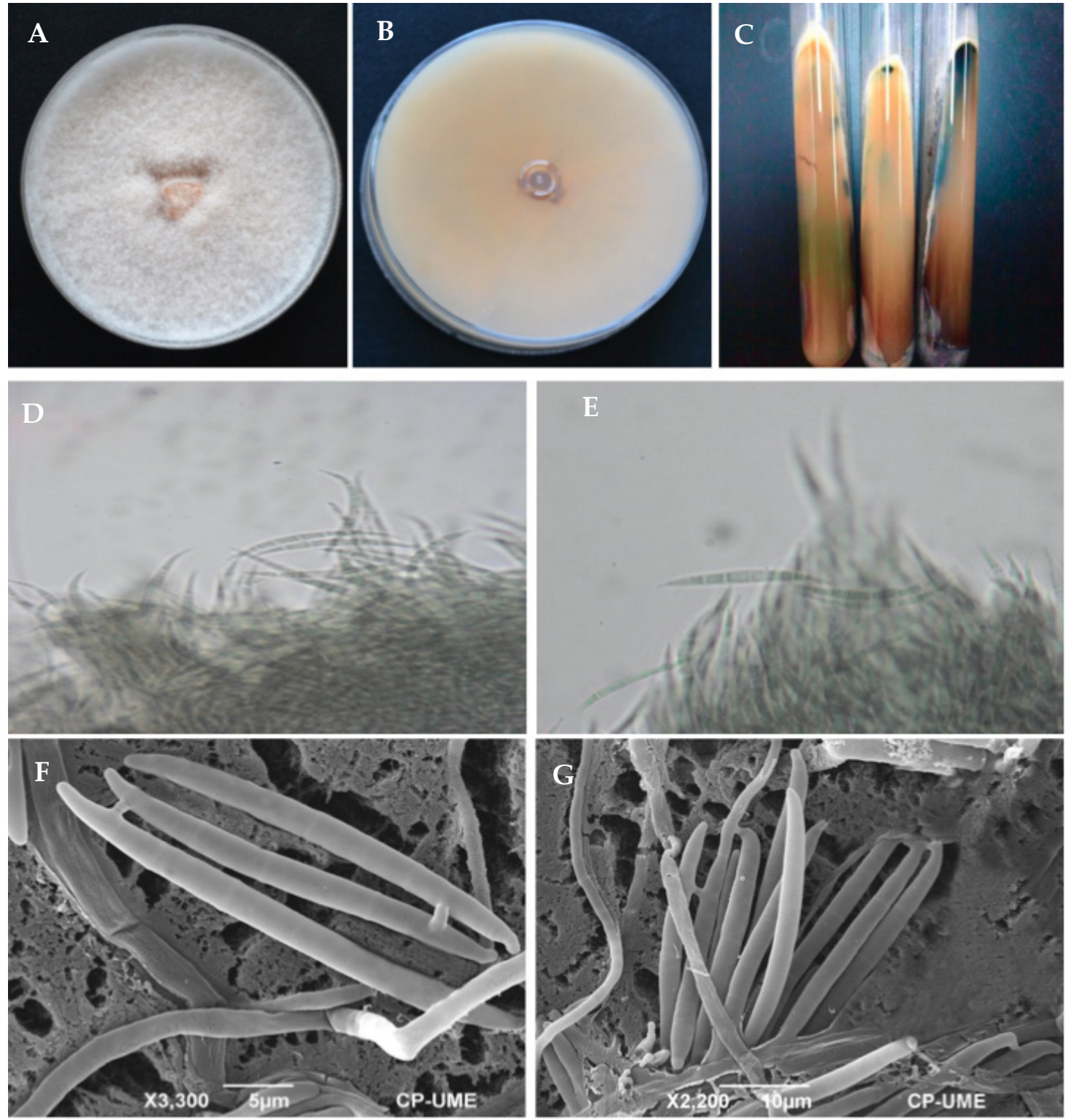

Fig. 2. Colonias y estructuras de reproducción de Fusarium graminearum. A y B) Colonia con crecimiento micelial de 10 días en medio de cultivo agar papa dextrosa; C) Colonia cultivada 10 días en tubos con medio de cultivo pulpa de papa; D-E) Macroconidios vistos con microscopio de luz; F-G) Macroconidios vistos en microscopio electrónico de barrido (MEB). Barras = 10 $\mu \mathrm{m}$.

Fig. 2. Colonies and reproductive structures of Fusarium graminearum. A and B) Colony with mycelial growth of $\mathbf{1 0}$ days on a potato dextrose agar medium; C) Colony grown for 10 days in tubes with potato pulp medium; D-E) Macroconidia as seen with a light microscope; F-G) Macroconidia as seen by scanning electron microscopy (SEM). Bars $=10 \mu \mathrm{m}$. 


\section{Análisis de secuencias y uso de iniciadores específicos}

La secuencia amplificada con los iniciadores ITS1/ITS4 para el aislado identificado morfológicamente como $F$. proliferatum, tuvo $99 \%$ de similitud con secuencias depositadas en la base de datos del GenBank pertenecientes a diversas especies de Fusarium. Lo anterior ocurrió porque estos iniciadores son universales y no son suficientes para identificar adecuadamente a las especies del género Fusarium (Aoki et al., 2014). De manera similar, al usar los iniciadores que amplifican parte del gen de factor de elongación (EF-1/EF-2), las similitudes fueron de $99 \%$ para $F$. proliferatum, $F$. verticillioides y $F$. oxysporum. Con esto no se logró un diagnóstico certero para la especie de Fusarium identificada morfológicamente como $F$. proliferatum, por lo cual se recurrió a los iniciadores PRO1 y PRO2 específicos para $F$. proliferatum, VER1 y VER2 usados para $F$. verticillioides y SUB1, SUB2 para $F$. subglutinans. Estos iniciadores permiten obtener un único producto de amplificación para cada una de estas tres especies, y en esta prueba de PCR fue positivo sólo para F. proliferatum, y no fue necesario corroborar por secuenciación debido a la especificidad de los oligos usados (Mulé et al., 2004).

Otra prueba de PCR se realizó con los oligos verITS-F, específico para F. verticillioides, y proITS-R, específico para $F$. proliferatum porque, como ya se indicó, estas dos especies son morfológicamente muy similares y es fácil confundirlas de acuerdo a la similitud de las estructuras de reproducción asexual (Leslie y Summerell, 2006; Visentin et al., 2009). La secuencia amplificada con estos iniciadores fue positiva sólo para F. proliferatum, y negativa para F. verticillioides. Asimismo, la discriminación con los oligos específicos es muy útil en estudios moleculares de especies fitopatógenas de Fusarium que presentan similitud en sus estructuras reproductivas (Visentin et al., 2009).

La secuencia amplificada con los iniciadores EF-1/EF-2 a partir del aislado identificado morfológicamente como F. graminearum, mostró $99 \%$ de similitud con diversas secuencias de $F$. graminearum depositadas en la base de datos del GenBank, confirmándose la identificación de esta especie.

\section{Prueba de patogenicidad y respuesta de variedades}

Doce días después de inocular las semillas de trigo con la suspensión de conidios de $F$. proliferatum y $F$. graminearum, las plántulas de todas las variedades de trigo mostraron síntomas evidentes de necrosis en la raíz. Lo anterior confirmó que la combinación de estas dos especies de hongos puede inducir los síntomas de necrosis y después causar pudrición total de raíces en las principales variedades de trigo en la región del Bajío de México. Este resultado dio pauta para realizar el análisis combinado de la respuesta de las 28 variedades de trigo a la infección por las dos especies de Fusarium, considerando que las infecciones naturales en un campo de trigo ocurren por más de una especie de este hongo. Además, el porcentaje de frecuencia de aislamiento de $F$. proliferatum $(60 \%)$ y $F$. graminearum $(40 \%)$ fue muy similar, y fue más conveniente evaluar el nivel de susceptibilidad de las 28 variedades de trigo usando la inoculación combinada de las dos especies, de acuerdo a lo sugerido por Fernandez y Chen (2005) y Gargouri-Kammoun et al. (2009). Considerando las medias de todas las variables evaluadas, encontramos que las variedades con mayor tolerancia fueron: Gálvez M87, Castrejón F97, Tlaxcala F2000 y Maya S2007, mientras que las que presentaron mayor susceptibilidad fueron: Monarca F2007, Chicalote FT, Altiplano F2007 y Batán F96.

En el caso de la germinación, el 39\% de las variedades mostró un 100\% de germinación en las semillas inoculadas con el hongo y en las semillas testigo (no inoculadas); estas variedades fueron Gálvez M87, Salamanca S86, Kronstad F2004, Cortázar S94, Don Carlos RT, Palmerin F2004, Tacupeto F2001, Santa Lucia, Torocahui S2004, Eneida F94 y Tlaxcala F2000. En la Tabla 1 se mencionan 11 variedades con $100 \%$ de germinación, lo cual es para puntualizar que estos datos se obtuvieron debido a que el experimento se desarrolló en invernadero, con $95 \%$ de humedad relativa y $22^{\circ} \mathrm{C}$, las cuales sugerimos que son condiciones óptimas o adecuadas para la germinación de la semilla de trigo. Para las variedades con un porcentaje de germinación menor al 70\% (Monarca F2007, Chicalote FT, Altiplano F2007 y Rebeca F2000) sí hubo un efecto directo debido a la inoculación, por lo cual estas variedades fueron más susceptibles al ataque del hongo en invernadero, mientras que en los testigos se tuvo $100 \%$ de germinación. Estos resultados coinciden con lo reportado por Gilbert et al. (2003), quienes indican que las semillas de trigo infestadas con $F$. graminearum mostraron un porcentaje de germinación menor al de las semillas no infestadas con tal patógeno.

En cuanto a la variable de necrosis de raíz, todas las variedades presentaron este efecto, pero variaron en su severidad. Las variedades Gálvez M87, Castrejón F97, Salamanca S86 y Maya S2007 obtuvieron las menores medias, lo cual significa que estas variedades presentan un nivel más alto de tolerancia a la infección por Fusarium spp. 
Tabla 1. Respuesta de variedades de trigo inoculadas con Fusarium spp. para las variables: porcentaje de germinación, porcentaje de necrosis de raíz, longitud de raíz, longitud del follaje.

Table 1. Response of wheat varieties inoculated with Fusarium spp. for the variables evaluated: percentage of germination, percentage of root necrosis, root length and foliage length.

\begin{tabular}{lcccc}
\hline \multicolumn{1}{c}{ Variedad } & $\begin{array}{c}\text { Germinación } \\
\mathbf{( \% )}\end{array}$ & $\begin{array}{c}\text { Necrosis de } \\
\text { raíz } \mathbf{( \% )}\end{array}$ & $\begin{array}{c}\text { Longitud de raíz } \\
(\mathbf{c m})\end{array}$ & $\begin{array}{c}\text { Longitud de } \\
\text { follaje } \\
\text { (cm) }\end{array}$ \\
\hline Altiplano F2007 & $52 \mathrm{D}$ & $34 \mathrm{ABC}$ & $5 \mathrm{CD}$ & $10 \mathrm{HIJ}$ \\
Bárcenas S2000 & $54 \mathrm{D}$ & $32 \mathrm{ABC}$ & $7,3 \mathrm{BCD}$ & $10,1 \mathrm{HIJ}$ \\
Batán F96 & $45 \mathrm{D}$ & $33 \mathrm{ABC}$ & $3,2 \mathrm{~F}$ & $10,5 \mathrm{GHI}$ \\
Castrejón F97 & $54 \mathrm{D}$ & $2 \mathrm{FG}$ & $10,6 \mathrm{~A}$ & $19,5 \mathrm{~A}$ \\
Chicalote FT & $49 \mathrm{D}$ & $46 \mathrm{AB}$ & $5 \mathrm{CD}$ & $9,5 \mathrm{HIJ}$ \\
Cortázar S94 & $100 \mathrm{~A}$ & $20 \mathrm{BCDE}$ & $8,3 \mathrm{ABC}$ & $12 \mathrm{DEF}$ \\
Don carlos T & $100 \mathrm{~A}$ & $21 \mathrm{BCD}$ & $7,4 \mathrm{BCD}$ & $10,5 \mathrm{GHI}$ \\
Eneida F94 & $100 \mathrm{~A}$ & $22,3 \mathrm{BCD}$ & $6,5 \mathrm{CD}$ & $10,4 \mathrm{GHI}$ \\
Gálvez M87 & $100 \mathrm{~A}$ & $0,1 \mathrm{G}$ & $11,8 \mathrm{~A}$ & $17,7 \mathrm{ABC}$ \\
Josecha F2007 & $47 \mathrm{D}$ & $45 \mathrm{AB}$ & $5,5 \mathrm{CD}$ & $9,7 \mathrm{HIJ}$ \\
Kronstad F2004 & $100 \mathrm{~A}$ & $22 \mathrm{BCD}$ & $8,1 \mathrm{ABC}$ & $10,1 \mathrm{HIJ}$ \\
Maya S2007 & $45 \mathrm{D}$ & $4 \mathrm{FG}$ & $8,9 \mathrm{ABC}$ & $17 \mathrm{ABC}$ \\
Monarca F2007 & $70 \mathrm{C}$ & $48 \mathrm{~A}$ & $3,7 \mathrm{EF}$ & $7,5 \mathrm{IJ}$ \\
Náhuatl F2000 & $50 \mathrm{D}$ & $44 \mathrm{AB}$ & $4,1 \mathrm{EF}$ & $7,7 \mathrm{IJ}$ \\
Nana F2007 & $46 \mathrm{D}$ & $1 \mathrm{FG}$ & $8,6 \mathrm{ABC}$ & $17,3 \mathrm{ABC}$ \\
Norteña F2007 & $14 \mathrm{G}$ & $2 \mathrm{FG}$ & $3,3 \mathrm{~F}$ & $8,1 \mathrm{IJ}$ \\
Palmerin F2004 & $100 \mathrm{~A}$ & $19 \mathrm{CDE}$ & $7,8 \mathrm{BCD}$ & $10,2 \mathrm{GHI}$ \\
Rebeca F2000 & $12 \mathrm{G}$ & $47 \mathrm{AB}$ & $4 \mathrm{EF}$ & $8 \mathrm{IJ}$ \\
Roelfs F2007 & $36 \mathrm{E}$ & $25 \mathrm{BC}$ & $9 \mathrm{AB}$ & $13,6 \mathrm{DEF}$ \\
Salamanca S86 & $100 \mathrm{~A}$ & $3 \mathrm{FG}$ & $4 \mathrm{EF}$ & $11 \mathrm{FG}$ \\
Santa Lucia & $100 \mathrm{~A}$ & $26 \mathrm{BC}$ & $5 \mathrm{CD}$ & $12,3 \mathrm{DEF}$ \\
Tlaxcala F2000 & $100 \mathrm{~A}$ & $26 \mathrm{BC}$ & $9,6 \mathrm{AB}$ & $18,5 \mathrm{AB}$ \\
Temporalera M87 & $80 \mathrm{BC}$ & $4 \mathrm{FG}$ & $4,7 \mathrm{DE}$ & $18,3 \mathrm{AB}$ \\
Triunfo F2004 & $50 \mathrm{D}$ & $22 \mathrm{BCD}$ & $8,2 \mathrm{ABC}$ & $16,3 \mathrm{ABC}$ \\
Tacupeto F2001 & $100 \mathrm{~A}$ & $27.5 \mathrm{BC}$ & $6,8 \mathrm{BCD}$ & $16,2 \mathrm{BCD}$ \\
Tobarito M97 & $88 \mathrm{~B}$ & $23 \mathrm{BCD}$ & $8,9 \mathrm{ABC}$ & $16,2 \mathrm{BCD}$ \\
Torocahui S2004 & $100 \mathrm{~A}$ & $29,9 \mathrm{BC}$ & $3,6 \mathrm{EF}$ & $7,8 \mathrm{IJ}$ \\
Urbina S2007 & $78 \mathrm{C}$ & $21,5 \mathrm{BCD}$ & $8,2 \mathrm{ABC}$ & $17,9 \mathrm{ABC}$ \\
\hline
\end{tabular}

* Medias con la misma letra en cada columna no son diferentes significativamente de acuerdo con la prueba $\operatorname{LSD}(P \leq 0,05)$.

* Means with the same letter in a column are not significantly different according to the LSD test $(P \leq 0.05)$.

Este resultado concuerda con lo señalado por Moreno-Gálvez et al. (1989), quienes indicaron que la variedad Gálvez M87 es moderadamente tolerante al ataque por Fusarium. Las variedades Monarca F2007, Chicalote FT, Altiplano F2007 y Batán F96 presentaron un grado mayor de necrosis en la raíz, confirmando que estas son las más sensibles a la infección por este hongo. Pero es importante mencionar que Monarca F2007 es inmune a la roya del tallo (Puccinia graminis f. sp. tritici), y moderadamente resistente a la roya de la hoja (Puccinia triticina) y roya amarilla (Puccinia striiformis f. sp. tritici) (Huerta-Espino et al., 2011), mientras que la variedad Altiplano F2007 es resistente a moderadamente resistente a $P$. triticina y P. striiformis f. sp. tritici (Villaseñor-Mir et al., 2014).

Con respecto a la variable longitud de raíz, Monarca F2007, Batán F96, Náhuatl F2000 y Rebeca F2000, tuvieron un valor menor debido a la inoculación de las dos especies de Fusarium, por tanto una mayor necrosis en su raíz y fueron las más susceptibles al ataque de ambas especies. Mientras que las variedades Gálvez M87, Castrejón F97, Tlaxcala F2000 y Maya S2007 mostraron mayor tolerancia al patógeno al presentar una longitud de raíz mayor a las demás.

Para la variable longitud de follaje, los 
resultados fueron muy similares a los de la longitud de raíz porque las variedades Monarca F2007, Chicalote FT, Altiplano F2007 y Batán F96 tuvieron una menor longitud de follaje. Así, estas variedades son susceptibles al ataque de las dos especies de Fusarium, y debido al daño en la raíz, la longitud del follaje fue menor. En cambio, las variedades Gálvez M87, Castrejón F97, Tlaxcala F2000 y Maya S2007 mostraron una mayor longitud de follaje.

Las variables longitud de raíz y longitud de follaje coincidieron para las variedades Gálvez M87, Castrejón F97, Tlaxcala F2000 y Maya S2007, las cuales tienen así un nivel más alto de tolerancia a esta enfermedad y coincide con el reporte de Villaseñor-Mir et al. (2000) de que Tlaxcala F2000 es tolerante al daño por $F$. graminearum. Mientras que las plantas testigo (no inoculadas) presentaron mayor longitud de follaje y raíz. Gálvez M87 fue una de las variedades que presentó el menor porcentaje de necrosis de raíz y la mayor longitud de raíz y follaje, por lo cual es la variedad más tolerante a la pudrición de raíz causada por Fusarium spp. Esto coincidió con lo reportado por Moreno-Gálvez et al. (1989) de que Gálvez M87 presenta moderada tolerancia a la infección por Fusarium. Sin embargo, esta variedad es susceptible a las enfermedades causadas por $P$. triticina y $P$. graminis $\mathrm{f}$. $\mathrm{sp}$. tritici (Villaseñor-Mir et al., 2014). La inoculación artificial de $F$. proliferatum y $F$. graminearum en semillas de 28 variedades de trigo, mostró que Gálvez M87, Castrejón F97 y Maya S2007 fueron las más tolerantes a la infección por Fusarium spp., mientras que Monarca F2007 y Batán F96 fueron las más sensibles.

\section{CONCLUSIONES}

Mediante la combinación de caracterización morfológica y molecular, así como pruebas de patogenicidad, se identificó a Fusarium proliferatum y $F$. graminearum como las especies causantes del síntoma de pudrición de raíz en plantas de trigo en campos del Bajío de México.

La inoculación de $F$. proliferatum y $F$. graminearum en semillas de 28 variedades de trigo, indicó que las variedades Gálvez M87, Castrejón F97 y Maya S2007 fueron las más tolerantes, mientras que Monarca F2007 y Batán F96 fueron las variedades más sensibles a la infección por Fusarium spp.

\section{AGRADECIMIENTOS}

Esta investigación se financió por el fondo SAGARPA-CONACYT a través del proyecto
No. 146788, asi como el proyecto E-26-2015 de la Universidad Autónoma Chapingo.

\section{LITERATURA CITADA}

Alvarez, C.L., S. Somma, A. Moretti, and V. Fernández-Pinto. 2010. Aggressiveness of Fusarium graminearum sensu stricto isolates in wheat kernels in Argentina. Journal of Phytopathology 158:173-181.

Aoki, T., K. O’Donnell, and D.M. Geiser. 2014. Systematics of key phytopathogenic Fusarium species: current status and future challenges. Journal of General Plant Pathology 80:189201.

Bozzola, J.J., and L.D. Russell. 2004. Electron microscopy: Principles and techniques for biologists. p. 16-63. 2nd. ed. Jones and Bartlett Publishers, New Jersey, England.

Chehri, K., B. Salleh, T. Yli-Mattila, M.J. Soleiman, and A.R. Yousefi. 2010. Occurrence, pathogenicity and distribution of Fusarium spp. in stored wheat seeds from Kermanshah province, Iran. Pak. J. Biol. Sci. 13:1178-1186.

Chelkowski, J., H. Wisniewska, T. Adamski, P. Golinski, Z. Kaczmarek, M. Kostecki, et al. 2000. Effect of Fusarium head blight on mycotoxin accumulation and yield traits in barley doubled haploids. Journal of Phytopathology 148:541-545.

Cook, R. J. 2010. Fusarium root, crown and foot roots and associated seedling diseases. p. 37-39. In Bockus, W.W., R.L. Bowden, R.M. Hunger, W.L. Morrill, T.D. Murray, and R.W. Smiley (eds.). Compendium of Wheat Diseases and Pests. 3rd. ed. APS Press, St. Paul, Minnesota, USA.

Fernandez, M.R., and Y. Chen. 2005. Pathogenicity of Fusarium species on different plant parts of spring wheat under controlled conditions. Plant Disease 89:164-169.

Gale, L.R., C.A. Hernick, K. Takamura, L.F. Chen, and H.C. Kistler. 2002. Population analysis of Fusarium graminearum from wheat fields in eastern China. Phytopathology 92:1315-1322.

Gargouri-Kammoun, L., S. Gargouri, S. Rezgui, M. Trifi, N. Bahri, and M.R. Hajlaoui. 2009. Pathogenicity and aggressiveness of Fusarium and Microdochium on wheat seedlings under controlled conditions. Tunis. J. Plant Prot. 4:135-144.

Gilbert, J., R.L. Conner, M.R. Fernandez, D. McLaren, and S.M. Woods. 2003. Role of spring wheat seed infested with Fusarium graminearum in spread and development of fusarium head blight and effects on agronomic performance. Canadian Journal of Plant Pathology 25:73-81. 
Gilchrist-Saavedra, L., G. Fuentes-Dávila, C. Martínez-Cano, R.M. López-Atilano, E. Duveiller, R.P. Singh, et al. 2005. Guía práctica para la identificación de algunas enfermedades de trigo y cebada. 68 p. 2a. ed. CIMMYT, México, D.F., México.

Hajieghrari, B. 2009. Wheat crown and root rotting fungi in Moghan area, Northwest of Iran. Afr. J. Biotechnol. 8:6214-6219.

Huerta-Espino, J., H.E. Villaseñor-Mir, E. SolísMoya, R. Sánchez-de la Cruz, y P. PérezHerrera. 2011. Monarca F2007: Nueva variedad de trigo harinero para el Bajío, norte y noroeste de México. Revista Mexicana de Ciencias Agrícolas 2(6):1001-1007.

Ireta M., J., y L. Gilchrist S. 1994. Roña o tizón de la espiga del trigo. 25 p. Informe Especial de Trigo No. 20. CIMMYT, México D.F., México.

Leslie, J.F., K.A. Zeller, M. Wohler, and B.A. Summerell. 2004. Interfertility of two mating populations in the Gibberella fuijuroi species complex. European Journal of Plant Pathology 110:610-618.

Leslie, J.F. and B.A. Summerell. 2006. The Fusarium Laboratory Manual. 369 p. Blackwell Publishing, Iowa, USA.

Moreno-Gálvez, R., E. Rodríguez-Pérez, J. HuertaEspino, y H.E. Villaseñor-Mir. 1989. Gálvez M87: variedad de trigo para temporal y riego restringido. 18 p. Folleto Técnico No. 14. INIFAP, Campo Experimental Valle de México, Chapingo, Estado de México, México.

Moschini, R.C., R. Pioli, M. Carmona, and O. Sacchi. 2001. Empirical predictions of wheat head blight in the Northern Argentinean Pampas Region. Crop Science 41:1541-1545.

Mulé, G., A. Susca, G. Stea, and A. Moretti. 2004. A species-specific PCR assay based on the calmodulin partial gene for the identification of Fusarium verticillioides, F. proliferatum and F. subglutinans. European Journal of Plant Pathology 110:495-502.

Muthomi, J.W., G.M. Riungu, J.K. Ndung'u, and R.D. Narla. 2007. Occurrence of wheat head blight and Fusarium species infecting wheat. Afri. Crop Sci. Conf. Proc. 8:863-867.

Nazar, R.N., X. Hu, J. Schmide, D. Gelham, and J. Robb. 1991. Potential use of PCR amplified ribosomal intergenic sequences in detection and differentiation of Verticillium wilt pathogens. Physiological and Molecular Plant Pathology 39:1-11.

Nelson, P.E., T.A. Toussoun, and W.F.O. Marasas. 1983. Fusarium Species: An Illustrated Manual for Identification. 193 p. Pennsylvania State University Press, University Park, Pennsylvania, USA.
Nicolaisen, M., S. Supronienė, N.L. Kærgaard, I. Lazzaro, S.N. Henrik, and J.A. Fejer. 2009. Real-time PCR for quantification of eleven individual Fusarium species in cereals. J. Microbiol. Meth. 76:234-240.

O'Donnell, K., H.C. Kistler, E. Cigelnik, and R.C. Ploetz. 1998. Multiple evolutionary origins of the fungus causing Panama disease of banana: Concordant evidence from nuclear and mitochondrial gene genealogies. Proc. Natl. Acad. Sci. 95:2044-2049

SIAP 2014. Servicio de Información Agroalimentaria y Pesquera (SIAP). Disponible en www. siap.sagarpa.gob.mx (Consulta 10 junio 2015).

Solís M.,E., S.A. Rios R., H. García, A. Arévalo, O.A. Grageda, M.A. Vuelvas, et al. 2007. Producción de trigo de riego en el Bajío. 94 p. Folleto Técnico $N^{\circ} 3$. INIFAP, Campo Experimental Bajío, Celaya, Guanajuato, México.

Villaseñor-Mir, H.E., E. Espitia-Rangel, J. HuertaEspino, A. María-Ramírez, L. Osorio-Alcalá, y D. Aguirre-Montoya. 2000. Tlaxcala F2000: Nueva variedad de trigo para siembras de temporal en México. 20 p. Folleto Técnico No. 1. INIFAP, Campo Experimental Valle de México, Chapingo, Estado de México, México.

Villaseñor-Mir, H.E., J. Huerta-Espino, E. EspitiaRangel, E. Solís-Moya, L. Osorio-Alcalá, J. Ireta Moreno, et al. 2014. Altiplano F2007, nueva variedad de trigo para siembras de temporal. Revista Mexicana de Ciencias Agrícolas 7:1355-1361.

Visentin, I., G. Tamietti, D. Velentino, E. Portis, P. Karlovsky, A. Moretti, et al. 2009. The ITS region as a taxonomic discriminator between Fusarium verticillioides and Fusarium proliferatum. Mycological Research 113:11371145.

White, T.J., T.D. Burns, S.B. Lee, and J.W. Taylor, 1990. Amplification and direct sequencing of fungal ribosomal RNA genes for phylogenetics. p. 315-322. In Innis, M.A, D.H. Gelfald, J.J. Sninsky, and T.J. White (eds.) PCR Protocol: A Guide to Methods and Application. Academic Press, Inc., New York, USA.

Xu, X.M., P. Nicholson, M.A. Thomsett, D. Simpson, B.M. Cooke, F.M. Doohan, et al. 2008. Relationship between the fungal complex causing Fusarium head blight of wheat and environmental conditions. Phytopathology 98:69-78. 